\title{
Optimizing Early Design Process Decision Making Through Effective Problem Framing
}

CLIFTON FORDHAM

Temple University

Building design and delivery activities, from programming to commissioning, draw on different strengths of architects including a unique form of problem solving that appears mysterious and personal. More common early in the design process, an intuitive approach, and a paucity of arguments connected to the financial interests of owners, masks the capacity of architects to provide valued adding integral sustainable design solutions which others can't effectively provide. An inclination toward intuition, and simulating early phase design problem solving, is consistent with how architecture schools teach, supplementing core studio curriculum with course work structured to introduce detailed knowledge. Within schools, this division is supported by the perception that numerical, and technical considerations, inhibit creativity and fluid output.

The degree to which this model fails to lead to rapid productivity of recent graduates has been a source of criticism from practitioners. Academics typically counter that they are interested in longer term critical thinking skills, and that it would be irresponsible to privilege the short term concerns of practitioners. This paper looks beyond the skills vs. thinking debate by relating core aspects of design thinking to opportunities available to optimize sustainable design earlier than later in the design process. It traces an experiment in introducing analytical tools to an undergraduate design studio course which demonstrates that objective feedback can co-exist with creative action, and points to the power of design at the schematic level when significant opportunities for sustainable design are cemented.

\section{PROBLEM SOLVING}

The building design process presents distinct challenges which influence the unique nature of architectural design education and practice. Other professionals are able to determine with relative effectiveness the objective of their design efforts by clearly identifying a range of acceptable outcomes which can be codified in explicit criteria and physical parameters. With clear parameters, they can anticipate what they will need to learn through analytical activity, consistent with the scientific model of gaining knowledge [Fig. 1]. A notion of problem identification as a discrete component of architectural design thinking is central to William Pena's book Problem Seeking which formalized the activity of programming. Because of the type of mindset necessary to ask adequate questions Pena argued that programming was best accomplished separately from design because it was methodical, and design is intuitive, although he acknowledge that a designer could program if of the correct mindset. ${ }^{1}$ Prior to Pena, architects including Christopher Alexander distinguished formal analysis and design activity with the aim of bolstering the efficacy of architects within a climate of increased confidence in science in the decades immediately following the Second World War. ${ }^{2}$

A scientific model of analysis and synthesis did not translate as well as promised to architectural design for several reasons. The first involved the amount of time that owners and architects had to develop a detailed program that identified comprehensive clear objectives. Second, although a detailed program could be developed, it was not possible to come to complete terms with the nature of a design problem before commencing design since building problems presented too many possible situations to analyze. A third reason involved the culture of architecture, where analytical activity that would lead to clear findings has been peripheral to alternative priorities in architectural studio education and practice.

Although counter to scientifically grounded thinking of engineers, deemphasis of analysis by architects is not completely irrational since ridged criteria can be a liability when seeking a wide range of potential outcomes. Architects are able to explore a wide range of potential solutions because analysis of problems does not preclude them from testing solutions that do not directly correspond to initial understandings of problems. More importantly, architects need to be able to learn about problems through posing solutions which contributes to a model of design thinking that advances on the analysis-synthesis model of design thinking [Fig. 2]. The notion of learning through solution reflection, as a method of addressing wicked problems which are disorderly, is credited to Donald Schon. ${ }^{3}$ 


\section{Basis for Refinement}

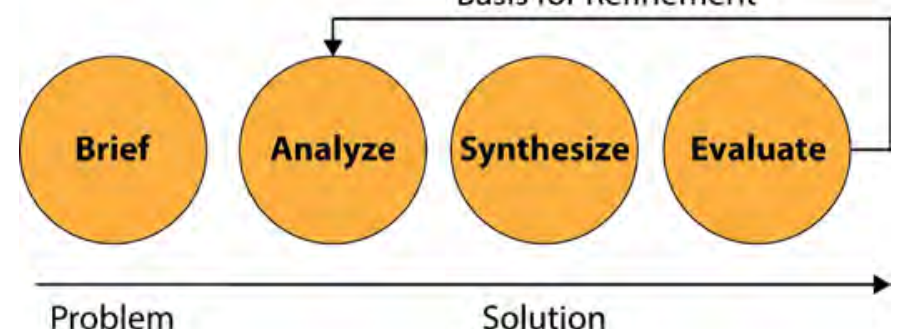

Figure 1: Analysis and synthesis model of problem solving.

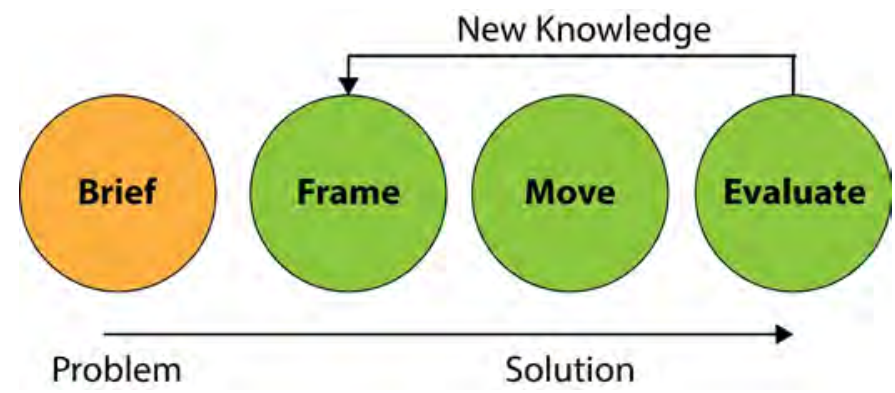

Figure 2. Learning through framing, solution posing, and evaluation model of problem solving.

In order to avoid paralysis and cut through almost unlimited problems and potentials, architects act intuitively by identifying issues to frame, and posing solutions that directly, or indirectly come from the territory framed. They can also import solutions external to the problem, which is a technique specific to architecture that plays a significant role in architecture school studio exercises.4 External solutions in the form of metaphors, typologies, or previous works, allow designers to cut across uncertainty and generate solutions by which problems can be better understood. Learning by doing, as opposed to learning by analysis, is particularly effective in the beginning stages of design when possibilities are vast, but less rewarding later in the design process when paths have been committed to, and specific problems become clearer and more technically demanding.

Broad gestural design moves need to occur within the realm of responsible solution posing. Experienced designers have accumulated knowledge that feeds intuitive abilities, can recognize situations, and determine when creative leaps are warranted. If a designer has not accumulated enough knowledge to assess situations, cannot make creative leaps, becomes paralyzed, is not critical, and can't learn from solutions, potential for effectiveness is limited. Beginning designers are presented with having to make intuitive decisions before they understand the implications of the design situations they are expected to sort through, and before they can effectively assess the decisions they make. The process of design education guides students to issues, and forms framing habits by which see design problems, and question results. ${ }^{5}$

The way architectural problem solving is introduced in the academy has implications for practice. Although architects have historically relied on learning in practice settings, the ramifications of design education are greater now, than in the past, since buildings are more technically complex and performance expectations are greater. Within individual building spaces, lighting, acoustic, and interior climate expectations have risen, and spaces accommodate demanding equipment, oftentimes suppressed in the building fabric This requires architects as coordinators to evaluate disparate systems within a context where other actors are approaching the design and building process with knowledge backed by science. More importantly, education establishes future values, and habits.

\section{CONNECTING TO THE BOTTOM LINE OF OWNERS}

Even though architects' responsibilities prior to the twentieth century included those of the modern general contractor, they currently have less credibility than general contractors and owner advisors with respect to understanding and controlling building costs. During construction, architects are often in the position of defending intentions which contractors claim were difficult, if not impossible to predict. Because proposed changes are framed as a value proposition, architects are generally forced to rationalize aesthetic decisions in the face of hard numbers from contractors. Often pressures to control construction costs eclipse perspective on long term benefits derived from quality designs that are sustainable, and contribute to a long building life.

Within a context of deliberation tied to building costs, architects who stubbornly defend higher costs without firm support for decisions, risk being perceived as frivolous or working counter to owner interests. A response to this dynamic includes communicating more pragmatically about construction, and cost issues, as well as linking design decisions to positive financial outcomes. Another avenue to more influence is to provide compelling reasons why form, material, systems, and finish expectations made early in the design process should not be compromised later. Many changes made under the guise of value engineering reduce the quality of buildings, and incur additional change charges. Potential additional construction charges garner exceptional attention eclipsing other issues. ${ }^{6}$

Labor expenditures during schematic design, which approximates studio design, are a fraction of those for design development, and construction documentation. After schematic design, the form of a building proposal is typically fixed and can only be slightly molded without upsetting schedule and work flows. Cost implications of making significant design changes late in the design process, is effectively captured in the MacLeamy Curve [Fig. 3]. Inherent in escalated costs for later changes is additional design work, but more importantly the cost of construction changes, both logistical and material. As a result opportunities to tweak a design to enhance its sustainability diminish throughout construction. Energy analysis, typically executed by engineers, generally occurs late in the design process after they have contributed the bulk of their labor.

When performance feedback is gained late in the design process, there is little chance to revisit early form decisions which could increase building performance. In this light, energy analysis typically acts as verification, as opposed to the basis for fundamental form adjustments, although valuable changes can occur with materials and details. Integral planning strategies, such as those executed at the Arup office building in central England can't be introduced later in the design process. The result is that most sustainable designs are a hybrid between early design process decisions made by architects intuitively, and late design process adjustments made based on hard analysis.? 


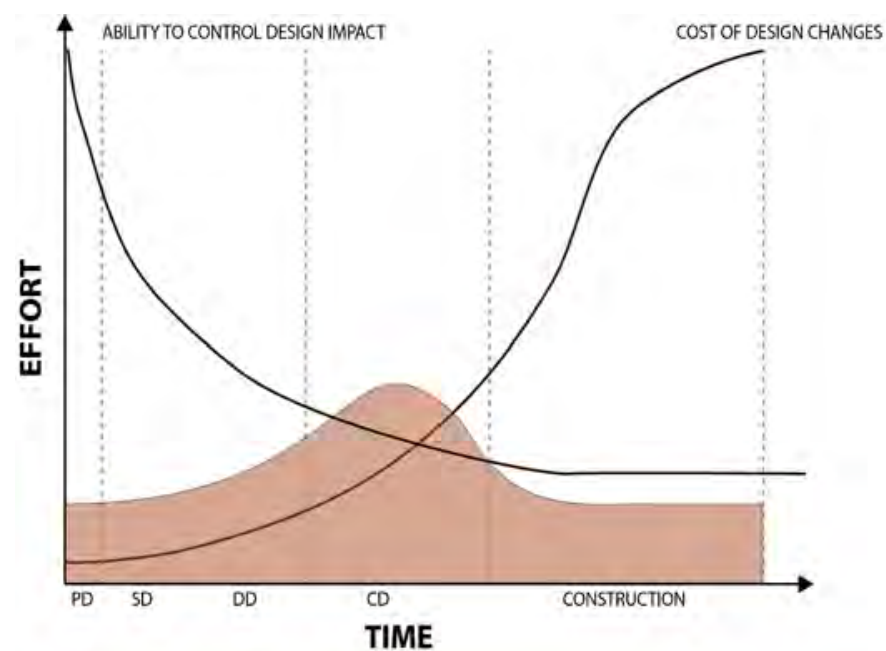

Figure 3. MacLeamy Curve.

\section{SUSTAINABILITY AS A VALUE PROPOSITION}

Sustainability has been typically framed against the negative environmental which have broad communal impacts, as opposed to benefits reaped directly by the building owners and users, and contractors. Greater focus of the building owner and occupant's interests broadens the appeal of sustainable design, and helps justify higher design and construction costs. Economic benefits include better energy performance, lower maintenance costs, greater user satisfaction and increased productivity; all of which can be tied to how well the building supports activity, comfort, and well-being. A less common sustainability concept points to a building's long term life being linked to its physical attractiveness motivating building owners and users to care for, and advocate for, a building that they consider beautiful. ${ }^{8}$

Finding increased value in form created early in the design process will increase understanding of architects' capabilities and value across projects of different building price points. Currently core architect talents are realized most fluidly in expensive expressive projects. Sustainably brings value, but it is rarely connected to early design decision making in a way that distinguishes benefits derived earlier than later in the design process. Utilizing software that provides early feedback supports sustainable building forms which are architect driven, permits integration of sustainability and form, and demonstrates that form is essential to building optimization.

Characteristics of vernacular buildings that work in harmony with local climate have been incorporated into architectural theory, and are integral to the thinking of many architects. Similarly non-vernacular concepts of solar design became part of the collective knowledge in the nineteen-fifties largely through the work of Aladar and Victor Olgyay, brothers who analyzed environmental forces in relation to what at the time were contemporary design strategies. By distilling solar design techniques and developing a language of visualizing the performance of buildings, the Olgyay brothers paved a path for architects to underpin solar design.

The Olgyay's research utilized scientific techniques including extensive mathematical calculations to support the principals they conveyed. These calculations were too cumbersome for most architects to apply to particular problems considering the fluid nature of design, and limits on time.

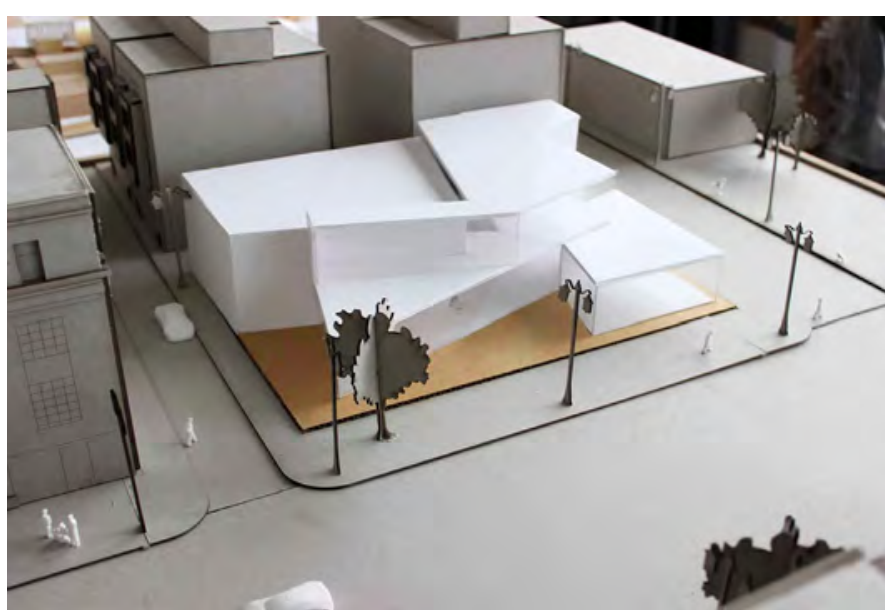

Figure 4. Student model at mid-term.

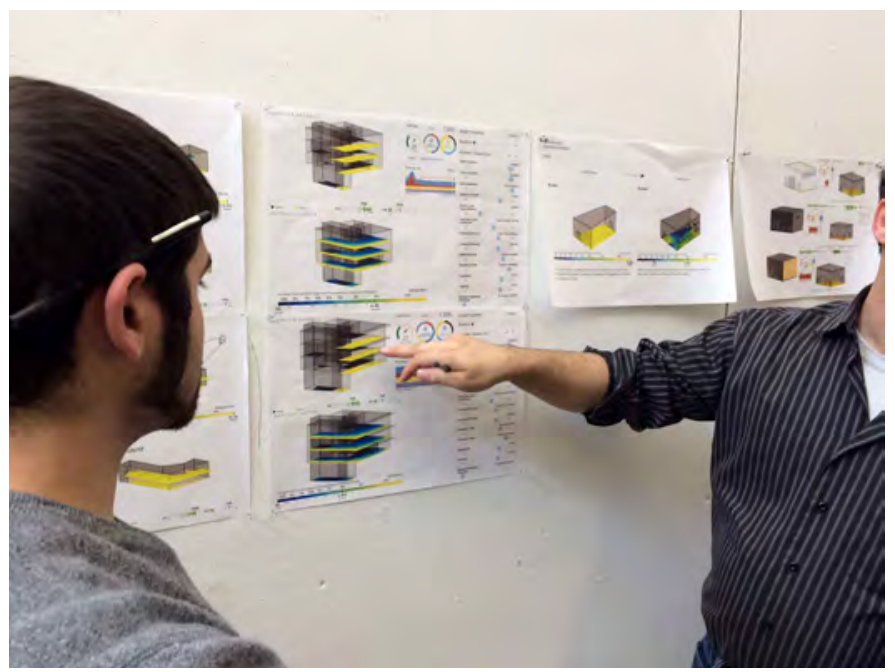

Figure 5. Discussion of design options using analysis printouts.

Alternatively, designers could utilize analogue tools including solar path diagrams, climate charts, and shaded design drawings; although it was more likely solar design would be intuitively applied and not explicitly demonstrated. Standard compensation models did not adapt to acknowledge additional time needed for calculations and drawings linked to solar design.

Strategically pointing to appealing forms helped the Olgyay brothers justify extra construction costs associated with solar shading strategies. In their book Solar Control and Shading Devices, the emphasis was on fenestration techniques, not building massing. In Victor Olgyay's later book Design with Climate: Bioclimatic Approach to Architectural Regionalism, massing and ventilation strategies are emphasized with few examples of appealing forms. Because principles and examples were more diagrammatic in the later book, architects were provided fewer familiar ways to justify design moves. Although style and recognition can move individuals to face costs, analyses complements judgment when emotion alone in not adequate to justify design.

\section{UNDERGRADUATE SUSTAINABILITY STUDIO}

Hurdles exist to introducing learning objectives that include building performance in early level design studio curriculum. Students have yet to develop 


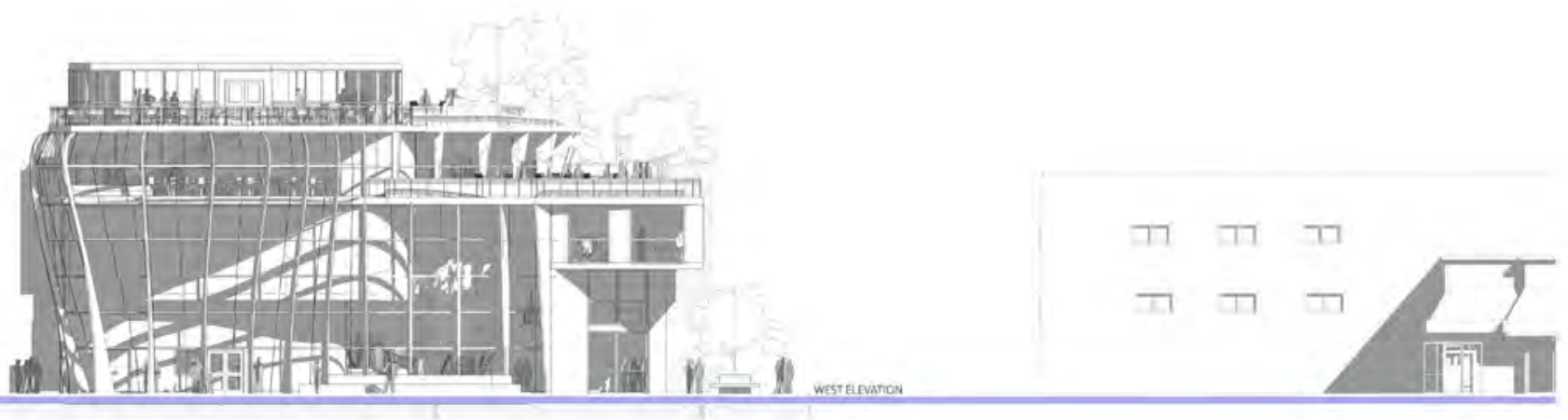

Figure 6. Section illustrating shading effects.

a personal design approach that they can confidently apply to different types of design problems. In most cases, they need guidance identifying design situations, recognizing key criteria, and generating concepts. Because of potential distractions, and limited knowledge of specific building requirements including egress, such factors are often omitted in studio projects to channel efforts towards more conceptual factors, and to allow for fluidity of form. Knowledge deemed important to architectural education, but is difficult to impart in studio settings, has traditionally been conveyed in support courses which are administered concurrently with studio courses, but seldom integrated until after graduation.

Learning objectives in the spring third year undergraduate studio at Temple University acknowledged challenges of integrating objective knowledge into studio exercises while addressing fundamental pragmatics including program and site. This semester the program was a Jazz Institute to include performance, practice, and exhibit space located on South Broad Street in Philadelphia. The public nature of the Jazz Institute program, and urban setting, engaged students in a design process that accounted for contextual site conditions including how the different program elements relate to the site, circulation, and views. Context also played a role in understanding the building in relation to sunlight, so factoring out site conditions was not an option. Students would also continue developing their ability to use abstract conceptual ideas to advance their proposals, a primary objective of the prior semester studio.

\section{PRELIMINARY EXERCISES TO MID-TERM}

Prior to engaging in building design students were asked to design a mobile performance pavilion. The week and-a-half project allowed critics to quickly gauge what the students have retained from the prior semester, and to have them to think quickly with limited dimensional constraints. After the sketch project, students were immersed in the history of jazz through documentaries, and individual research of seminal jazz artists. In order to provide additional visual material to bring to their design proposals, students were ask to associate found abstract images with qualities of music, instruments, and performance. Site research involved photographing and surveying the site, resulting in a digital base model and an eighth-scale physical site model From the digital model, they developed photomontages, contextual street wall elevations, and two-dimensional site sections that included seasonal sun paths. Students were also asked to submit a notebook of key observations made at the site.
After research and concept mining activities, students were issued a detailed building program with area requirements. During the next three weeks excluding spring break, the students were tasked with translating the building program in to two dimensional relationship diagrams, a three dimensional conceptual collage model, plans, and building sections. Development of individual building design proposals necessitated programming instruction including how to interpret, and manage a program. The first building design phase culminated soon after spring break leaving five weeks for design prior to the final review.

\section{POST MIDTERM}

The first three weeks of building design allowed students to develop a rough proposal [Fig. 4] that would provide the basis of further development over the following five weeks to include energy analysis. Introducing energy modeling as a means of providing feedback during the design process necessitated software instruction, which at Temple, is imbedded in studio courses. Prior to the mid-term most of the work was in analogue form with some modeling in Rhino, which is the platform the students have been grounded in, and the program they are comfortable with. Since it was important to have students be able to work fluidly while learning about jazz, and how to work with a complex program and site, students were introduced to new software midway into the semester.

In prior semesters many students were reluctant to learn and use software they perceived as burdensome in light of the challenges they faced dealing with new expectations. Digital instruction in a lab also contributed to the perception they were losing time advancing their designs. For this reason, it was important that the digital sessions not be understood as supplemental, but rather as integral to their design objectives. Rather than acquiesce to student biases, and preconceived notions of what is useful, adjustments included using energy modeling software that was user friendly for schematic design. Sefaira was the chosen analysis platform which necessitated instruction in Revit, a program that is associated with cumbersome detail. A response was to focus on the massing capabilities of Revit, and not get bogged down in features of Revit that would not contribute directly to analysis in Sefaira. Students were taught how to transfer file information between Rhino to Revit, something that would help them to see that their efforts in one platform would not go to waste by building redundant models.

\section{BALANCE BETWEEN PERFORMANCE AND BEAUTY}

Lectures and assignments involving principles of sustainable design were interwoven into digital sessions creating fluidity between the studio and lab. Building examples, including notable designs and vernacular, were used to 


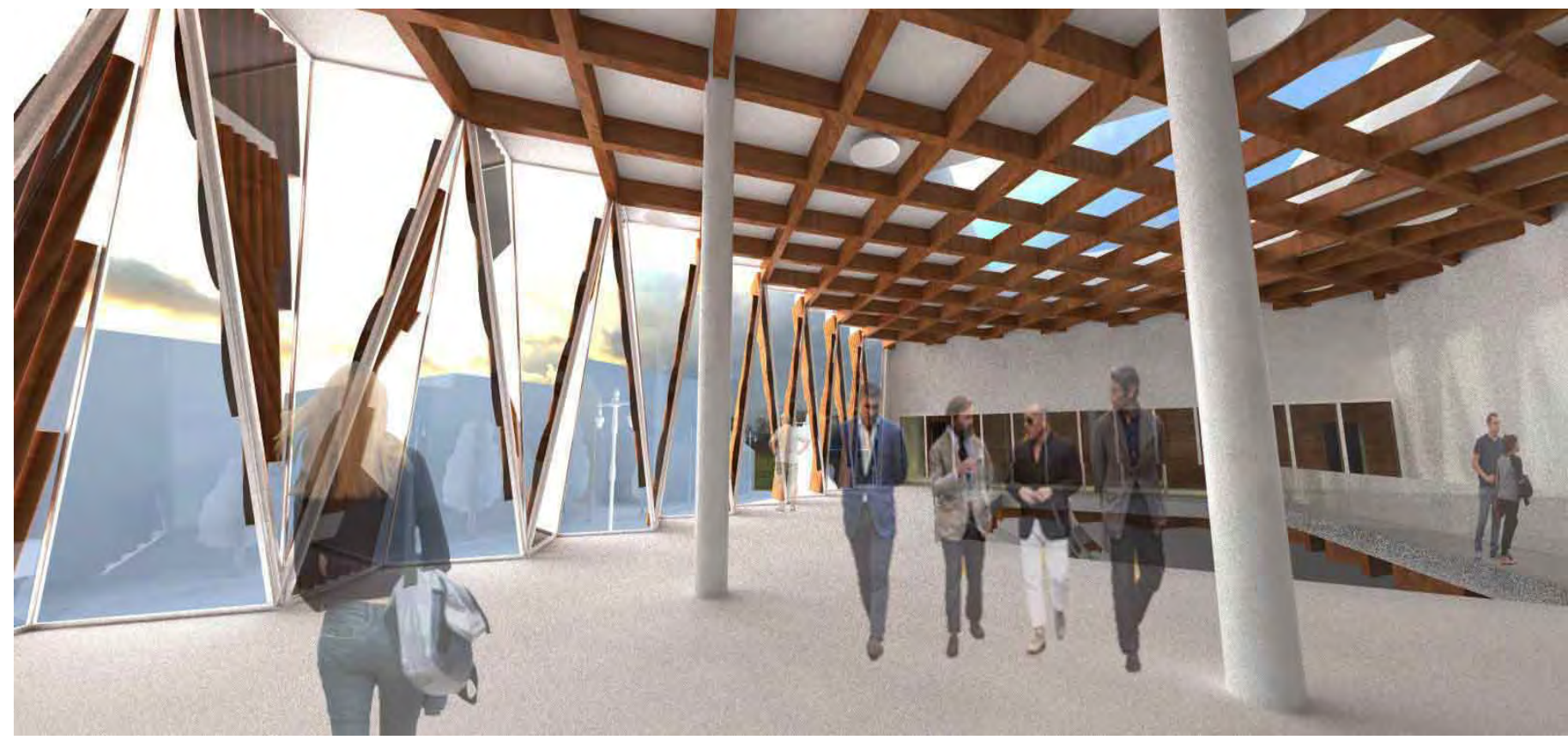

Figure 7. Interior rendering of final proposal.

make connections between sustainability and form. These efforts helped counter the perception that the lab time was just technical instruction. In addition to diagraming their design process, assignments included precedent analysis of green buildings in where they were asked to question how the examples are sustainable.

After learning how to translate between Rhino and Revit, students constructed simple massing models to see how form changes contributed to different readings in Sefaira. They modeled different iterations of their proposals and produced analytical reports. The results were presented in group pin-ups [Fig. 5] so students could learn from each other's efforts, and could see that evaluating data along with abstract representations of their designs was a compatible method of designing. As a result, students advanced their designs with the understanding that changes to massing, orientation, glazing areas or shading would result in different performance outcomes.

Throughout the semester students were taught that design is about balance between competing criteria including energy performance and aesthetics. Absolute improvements in energy performance without creating pleasing spaces, and sound juxtapositions, would be no more valuable than aesthetic achievements without functional and performance. As designers they would be responsible for coming to terms with tradeoffs, and identifying a proposal that recognized the impacts of decision making. In order to produce compelling designs, and convey their ideas presentation standards including crafted models, and perspective renderings were still emphasized. To assist with conveying their ideas, especially performative, students were provided support with representing building performance diagrammatically.

\section{CONCLUSION}

Introducing pragmatic considerations early, as opposed to later in the studio sequence, was seen as more important than deferring integration at a later period in the student's development. With tools such as Sefaira which are fluid and provide quantitative feedback, verifiable sustainable design thinking can be part of the next generation's foundational thinking skills. This studio challenged the belief that scientific principles and data and data could coexist with creativity activity without undermining the development of fundamental design skills. Key to this effort was persistent effort to have the students identify constraints that can contribute to design responses, and to identify external inspiration that they could consciously introduce into proposals.

\section{ENDNOTES}

1. Pena, William, Problem Seeking, CBI, Boston, 1977, 14-22.

2. See Alexander's book Notes on the Synthesis of Form first published in 1964 Alexander breaks down design problems into mathematical modules that can be used to construct solutions.

3. Schon, Donald. Educating the Reflective Practitioner, Jossey-Bass, San Francisco, 1990, 3-6.

4. Schon, Donald. The Design Studio, RIBA Publications, London, 1985, 15-17.

5. Lawson, Bryan \& Dorst, Kees. Design Expertise, Architectural Press, Oxford, 2009, 82-104.

6. The field of behavioral economics has contributed greatly to establishing that humans are completely rational actors when approaching economic decisions. Economists have been successful in pointing out that the psychological pain of loss is greater than pleasure gained for the same magnitude.

7. The ARUP campus in Solhill, England is a contemporary building opened in 2005 and designed by the firm. It is shaped to allow for passive cooling and heading.

8. Hosey, Lance, The Shape of Green, Island Press, Washington, DC, 2012, 39-47, 98-101. 